\title{
Gender based differences in clinical and Angiographic characteristics and outcomes of Acute Coronary Syndrome (ACS) in Asian population
}

\author{
Afrasyab Altaf ${ }^{1}$, Hammad Shah ${ }^{2}$, \\ Momin Salahuddin ${ }^{3}$
}

\begin{abstract}
Objective: There is very limited data about gender based differences in Acute Coronary Syndrome (ACS) in Asian population. This study was therefore aimed to ascertain gender based differences in clinical and angiographic characteristics and clinical outcomes in patient admitted with ACS.

Methods: This was a cross sectional, observational study including patients admitted with diagnosis of ACS. Patients were divided into two groups (Males and Females) and their clinical characteristics were noted. Gender based assessment was done following coronary angiography.

Results: A total of 386 patients were included, with 210 males and 176 females. Anterior wall myocardial infarction (AWMI) was present in $177(45.86 \%$ ) patients. Mean age was $72.8 \pm 12.9$ years in females and $66.8 \pm 11.2$ years in males. Diabetes was present in $38.1 \%$ females and $31 \%$ males. Patients from rural population were $225(58.3 \%)$, while from urban $161(41.7 \%)$. Mean ejection fraction was $43.9 \pm 7.9 \%$ in women and $38.2 \pm 8.68 \%$ in males.

Conclusion: ACS was more common in males, rural population and AWMI was most common cause. Women were more elderly and had more adverse events as compared to males. Impaired renal dynamics were more commonly observed in males. Women were less aggressively treated with coronary interventions and radial approach was better tolerated regardless of gender.
\end{abstract}

KEYWORDS: Acute Coronary Syndrome, Angiographic characteristics, Clinical Outcomes, Gender.

doi: https://doi.org/10.12669/pjms.35.5.743

How to cite this:

Altaf A, Shah H, Salahuddin M. Gender based differences in clinical and Angiographic characteristics and outcomes of Acute Coronary Syndrome (ACS) in Asian population. Pak J Med Sci. 2019;35(5):1349-1354. doi: https://doi.org/10.12669/pjms.35.5.743

This is an Open Access article distributed under the terms of the Creative Commons Attribution License (http://creativecommons.org/licenses/by/3.0), which permits unrestricted use, distribution, and reproduction in any medium, provided the original work is properly cited.

\section{INTRODUCTION}

Acute Coronary Syndrome (ACS) is characterized by decreased perfusion of heart muscles, which includes unstable angina and myocardial infarction. ${ }^{1}$ Myocardial infarction is diagnosed by rise or fall of cardiac biomarkers, with addition of any one of other classic features like ischemic symptoms, dynamic ECG changes, new onset LBBB, evidence of loss of viable myocardium, appearance of new regional wall motion abnormality or presence of intracoronary thrombus. ${ }^{2}$

Rise in cardiac biomarkers predict severity of coronary stenosis ${ }^{3}$ but another study showed severe stenosis was not predictor of myocardial

* Received for Publication: $\quad$ October 3,2018 
infarction and ACS occurred with mild to moderate stenosis in majority of patients. ${ }^{4}$ Vulnerable plaque rupture predict the occurrence of ACS. ${ }^{5}$ According to pathological studies TCFA(Thin Cap Fibro Atheroma) is main type of vulnerable plaque susceptible to rupture. ${ }^{6}$ Actual frequency of plaque rupture is low and doesn't exhibit clinically, therefore additional factors including increased blood vulnerability has been hypothesized to contribute to clinical manifestation of ACS besides vulnerable plaque rupture. ${ }^{7}$

Age is important factor determining outcome of ACS and elderly patients have very high in hospital mortality because they are given palliative treatment mostly ${ }^{8}$ and do not get optimum recommended treatment. ${ }^{9}$ Similarly gender also affects ACS outcome but we have conflicting contradictory evidence. Increased incidence of adverse events was observed in women undergoing early invasive strategy, ${ }^{10}$ but overall long term survival was better in woman as compared to men. ${ }^{11}$

There is very limited data about gender differences in clinical features, angiographic characteristics and ACS outcomes in Asian population. This study was therefore aimed to ascertain gender based differences in clinical features, angiographic characteristics and outcome of Asian patients admitted with ACS presenting to a tertiary care hospital.

\section{METHODS}

This was a cross sectional, descriptive, observation study carried out at cardiology department of Rehman Medical Institute from $01^{\text {st }}$ Jan, 2018 to $30^{\text {th }}$ Jun 2018 a period of six months. A total of 386 patients were included in the study population using universal sampling technique. All those patients were included who were admitted or discharged with diagnosis of acute coronary syndrome fulfilling the criteria of either unstable angina or myocardial infarction. ${ }^{2}$ Patients who were admitted due to non-cardiac causes like severe pneumonia, ARDS, and renal failure were excluded from the study population. Data were collected using a printed questionnaire. Informed written consent was obtained and confidentiality of the patients was ensured.

Mechanical Complications included ventricular septal defect, ischemic mitral regurgitation, pericardial effusion and free wall rupture confirmed on echocardiography. Heart failure was defined according to NYHA (New York Heart Association) classification. Bundle branch block was diagnosed as presence of new onset right or left bundle branch block on ECG. Arrhythmias were broadly termed for all the supraventricular and ventricular electrical abnormalities documented on ECG. Renal dysfunction was worsening of serum creatinine more than double of the baseline during 24 hours. Left Ventricular Ejection Fraction was assessed using Left Ventricular End Diastolic Dimensions and Left Ventricular End Systolic Dimensions by modified Simpson's method. ${ }^{12}$

This study was approved by research evaluation unit of Rehman Medical Institute after scrutiny of synopsis and abided by the declaration of Helsinki.

Data Analysis: Data was analyzed by SPSS 20. The Shapiro-Wilk test was applied to check the distribution of data. Mean \pm Standard Deviation was determined for quantitative variables. Qualitative variables were expressed as frequencies and percentages. Chi Square test and Fischer exact test was used to assess the association between qualitative variables and gender. Independent T-test was applied to analyze gender association with quantitative variable. $P$-value of less than 0.05 was considered as significant.

\section{RESULTS}

A total of 386 patients were admitted with diagnoses of ACS with 210 (54.4\%) males and 176 (45.6\%) females. Among total patients, 177 (45.86\%) patients had anterior wall myocardial infarction, $84(21.8 \%)$ patients had inferior myocardial infarction, $38(9.8 \%)$ patients had NSTEMI and $19(4.9 \%)$ patients had unstable angina. Mean hospital stay was $2.8 \pm 1.8$ days. Diabetes was more commonly observed in females as compared to male patients. A total of $225(58.3 \%)$ were from rural population and $161(41.7 \%)$ were from urban (Table-I).

Male patients had more adverse renal dynamics then female patients and had a greater propensity of heart blocks. However, overall adverse events were more frequently observed in women as compared to men leading to increase in mean hospital stay among women patients as compared to men. Gender based details of ACS outcomes are shown in Fig.1.

Coronary interventions were carried out in 186 (48.1\%) patients of ACS admitted to RMI among whom $120(31 \%)$ were males and $66(17.1 \%)$ were 
Table-I: Baseline characteristics of study group.

\begin{tabular}{|c|c|c|c|}
\hline Variable & Male $(n=210)$ & Female $(n=176)$ & P-value \\
\hline $\begin{array}{l}\text { Age (Years) } \\
\text { Body Mass Index }\left(\mathrm{kg} / \mathrm{m}^{2}\right) \\
\text { Population } \\
\text { Rural } \\
\text { Urban } \\
\text { Diabetes } \\
\text { Hypertension } \\
\text { Hyperlipidemia } \\
\text { Smoking } \\
\text { Ejection Fraction } \\
\text { NYHA Class } \\
\text { Hospital Stay (days) } \\
\text { Heart Failure } \\
\text { In hospital Treatment } \\
\text { Aspirin } \\
\text { Clopidogrel } \\
\text { Beta Blockers } \\
\text { CCBs } \\
\text { Digoxin } \\
\text { Ivabradine } \\
\text { ACEI } \\
\text { ARBs } \\
\text { Statins } \\
\text { Ionotropes } \\
\text { Enoxaparin } \\
\text { Heparin } \\
\text { Tirofiban } \\
\text { Rivaroxeban }\end{array}$ & $\begin{array}{c}197(93.8 \%) \\
188(89.5 \%) \\
174(82.8 \%) \\
17(8.1 \%) \\
30(14.3 \%) \\
80(38.1 \%) \\
166(79 \%) \\
132(62.8 \%) \\
185(88.1 \%) \\
84(40 \%) \\
193(91.9 \%) \\
16(7.6 \%) \\
9(4.3 \%) \\
12(5.7 \%)\end{array}$ & $\begin{array}{c}159(90.3 \%) \\
162(92 \%) \\
141(80.1 \%) \\
11(6.2 \%) \\
20(11.4 \%) \\
58((32.9 \%) \\
134(76.1 \%) \\
105(59.6 \%) \\
144(81.6 \%) \\
58(32.9 \%) \\
157(89.2 \%) \\
9(5.1 \%) \\
11(6.2 \%) \\
8(4.5 \%)\end{array}$ & $\begin{array}{l}0.046 \\
0.071 \\
0.066 \\
0.077 \\
0.024 \\
0.088 \\
0.066 \\
<0.01 \\
0.044 \\
0.063 \\
0.061 \\
0.091\end{array}$ \\
\hline
\end{tabular}

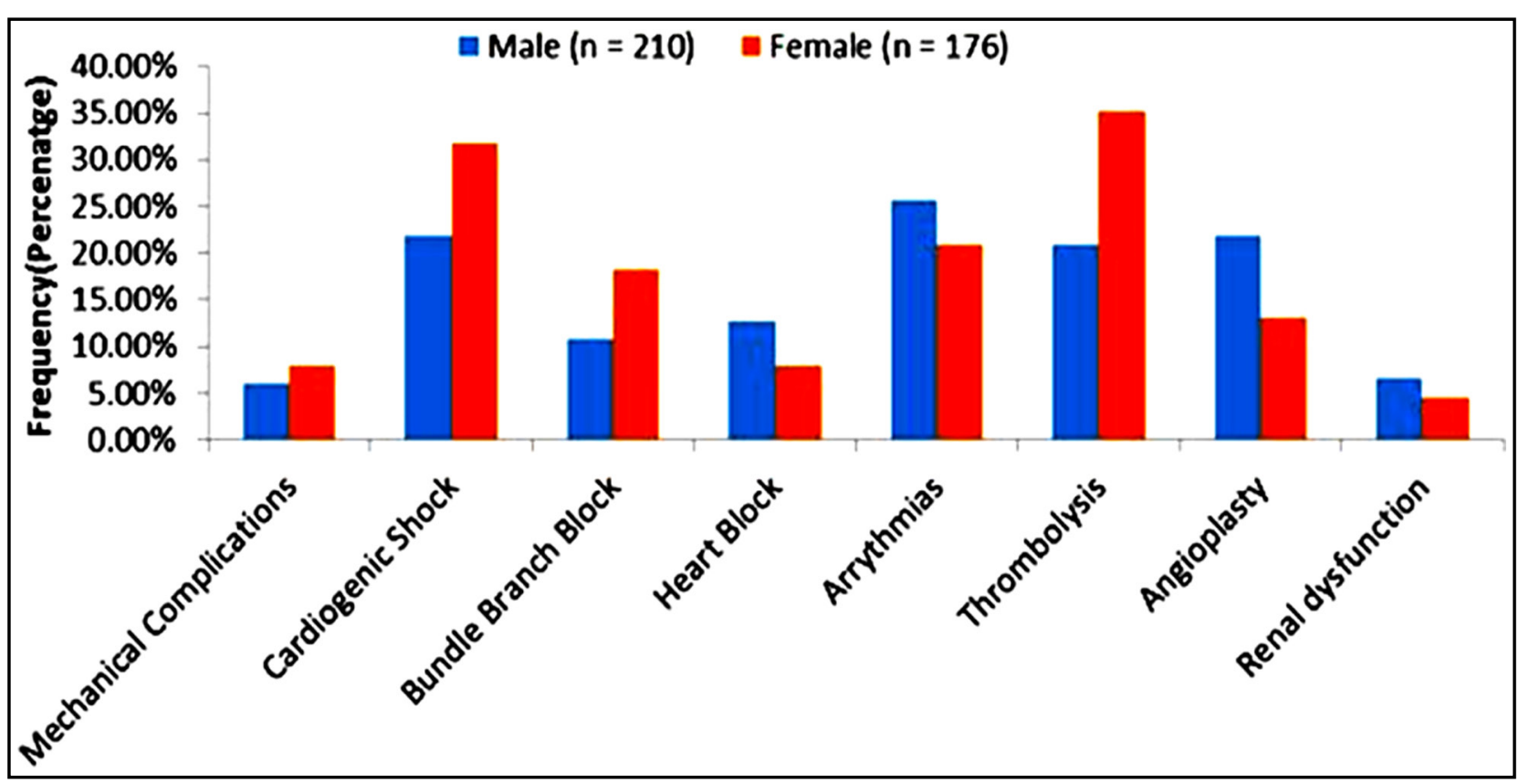

Fig.1: ACS outcomes in male and female patients. 
Table-II: Coronary Angiography Characteristics and Procedure Outcomes in ACS.

\begin{tabular}{|c|c|c|c|}
\hline Variable & Male $(n=120)$ & Female $(n=66)$ & P-value \\
\hline $\begin{array}{l}\text { Coronary Angiography } \\
\text { Radial Approach } \\
\text { Femoral Approach } \\
\text { SVCAD } \\
\text { DVCAD } \\
\text { TVCAD } \\
\text { LMS Disease } \\
\text { LAD Disease } \\
\text { RCA Disease } \\
\text { Circumflex Disease } \\
\text { Single vessel PCI } \\
\text { Multi Vessel PCI } \\
\text { POBA Only } \\
\text { Hematoma Formation } \\
\text { Blood Transfusions }\end{array}$ & $\begin{array}{c}79(65.8 \%) \\
41(34.2 \%) \\
25(20.8 \%) \\
30(25 \%) \\
63(52.5 \%) \\
17(14.2 \%) \\
98(81.7 \%) \\
76(63.3 \%) \\
88(73.3 \%) \\
68(54.2 \%) \\
57(47.5 \%) \\
2(1.7 \%) \\
6(5 \%) \\
1(0.8 \%)\end{array}$ & $\begin{array}{c}46(69.7 \%) \\
20(30.3 \%) \\
15(22.7 \%) \\
18(27.3 \%) \\
37(56.1 \%) \\
9(13.6 \%) \\
56(84.8 \%) \\
42(63.6 \%) \\
50(75.8 \%) \\
29(43.9 \%) \\
28(42.5 \%) \\
2(3 \%) \\
4(6 \%) \\
1(1.5 \%)\end{array}$ & $\begin{array}{l}0.063 \\
0.071 \\
0.083 \\
0.061 \\
0.058 \\
0.066 \\
0.081 \\
0.099 \\
0.061 \\
0.033 \\
0.041 \\
0.089 \\
0.073 \\
0.066\end{array}$ \\
\hline
\end{tabular}

females. Radial approach was better tolerated and had less hematological adverse events. More than half of the patients $100(53.1 \%)$ were suffering from triple vessel coronary artery disease and LAD 154 $(81.9 \%)$ was the most common coronary artery affected followed by Left circumflex 138 (73.4\%) and right coronary artery $118(62.8 \%)$. Left main stem was involved in $26(13.8 \%)$ of the patients as shown in Table-II.

\section{DISCUSSION}

Adequate evidence exists about age influencing ACS outcomes, but there are contradictory reports about gender effects on ACS outcomes globally. Some studies predict higher in hospital mortality for female patients, ${ }^{13}$ some report more adverse events in elder female patients, ${ }^{8}$ while others advocate no difference in mortality and better long-term survival of women patients. ${ }^{11} \mathrm{No}$ data exists about epidemiology of Asian population gender effects on clinical features, angiographic characteristics and outcomes of ACS patients. This study was therefore aimed to provide subjective evidence of gender based differences in clinical features, angiographic characteristics and outcomes of Asian patients admitted with ACS presenting to a tertiary care hospital.

In a prospective cohort study involving 2,135 subjects, transition from gradual to rapid increase in incidence of ACS occurred earlier in men (51-55 year) as compared to women (56-60yr). ${ }^{14}$ Men had increased overall incidence of ACS than women $(24.1 \%$ vs. $17.0 \%)$ and had higher incidence in corresponding age groups aswell. ${ }^{14}$ Our results showed preponderance of males, among patients admitted with ACS and women were more elderly at presentation as compared to men. Late increase in slow to rapid transition in women provides reasonable explanation to higher mean age of women than men observed in our results among patients of ACS.

Our results showed that majority of ACS patients were from rural population as compared to urban. Similar comparable findings were observed in Pakistani subjects where 63.2\% were from rural area and $36.8 \%$ from urban. Prevalence of hyperhomocystenemia was documented as higher in northern population and male patients, ${ }^{15}$ and hyperhomocystenemia has positive correlation with coronary artery disease. ${ }^{16}$ Moreover, majority of our population lives in rural area. ${ }^{17}$ All these factors explain our results of raised incidence of ACS among subjects from rural areas and preponderance of male patients among total patients admitted with diagnosis of ACS.

Anterior wall myocardial infarction was most common cause of ACS accounting for $45.8 \%$ cases in our study population. Our results were consistent with other international studies which reported anterior wall myocardial infarction as leading cause of STEMI accounting for 55\% cases. ${ }^{18}$ The difference in frequencies is due to different population selection. Our study population included all ACS patients having both STEMI and NSTEMI. Rajhans R et al, studied only 50 patients with STEMI leading to higher overall percentages in their results. ${ }^{18}$ 
Incidence of diabetes is reported to be more in females internationally ${ }^{11}$ and similar trend was observed in our population where majority of patients with diabetes mellitus were females (38.1\% against $31 \%$ with $p=0.024)$. Women had more mean ejection fraction of $43.9 \pm 7.9 \%$ against $38.2 \pm 8.68 \%$ in males $(\mathrm{p}$ value $=0.044)$ because women have increased prevalence of heart failure with preserved ejection fraction. ${ }^{19}$ Another study reports male patients to have more right ventricular mass and right ventricular volume but lower ejection fraction then females due to sex hormones even in non-heart failure patients. ${ }^{20}$ These factors might have influenced the mean difference in ejection fraction observed in our study population.

Men had adverse renal dynamics than females in our subjects because women were less frequently exposed to interventions. Majority of our subjects have underlying renal dysfunction. ${ }^{21}$ Coronary interventions affects renal dynamics further by directly inducing contrast nephropathy and secondarily causing decreased renal perfusion due to more blood loss during coronary interventions. Radial approach was better tolerated because it had less frequent hematologic side effects than femoral approach.

Our results showed that apart from better renal dynamics women generally had more adverse events as compared to men because women were elder at presentation and they had greater comorbidity like diabetes, as compared to male patients. Different international studies support our results. Udell JA et al. ${ }^{22}$ reported increased number of overall adverse events in women as compared to male patients.

Heart failure is a poor prognostic factor after ACS and its incidence increases steeply with age. ${ }^{23}$ Although Torabi A et al., results showed adverse prognostic value of heart failure development after ACS but they failed to show actual disease burden in community. Our results showed $18.2 \%$ incidence of heart failure in women against $17.1 \%$ in male patients with $\mathrm{p}$ value of 0.66 showing no significant gender associated difference. ${ }^{23}$

Arrhythmias and cardiogenic shock were more frequently reported in female patients as compared to male patients. Females had less frequently undergone coronary interventions and more thrombolysis than their male counterparts. Streptokinase is the most common thrombolytic used in underdeveloped countries and arrhythmias along with hypotension are its well-recognized most common side effects. ${ }^{24}$ This explains the higher incidence of shock and arrhythmias in female patients of our study population.

Limitations: Having been a cross sectional single centered study, the trends in general population cannot be truly predicted from our results, but it will serve as a platform for further population based studies.

\section{CONCLUSION}

Incidence of ACS in Asian population is more in males, rural population and AWMI was its most common cause. Women were generally elder at presentation and suffer more frequently from adverse events. Impaired renal side effects and heart blocks were more common in male patients. Women were less aggressively treated with coronary interventions and radial approach was better tolerated in both genders.

\section{Declaration of Interest: None.}

Source of Funding: None.

\section{REFERENCES}

1. Fanaroff AC, Rymer JA, Goldstein SA. Acute Coronary Syndrome. JAMA. 2015;314(18):1990. doi: 10.1001/ jama.2015.12743.

2. Thygesen K, Alpert JS, Jaffe AS, Simoons ML, Chaitman BR, White HD. Third universal definition of myocardial infarction. Circulation. 2012;126(16):2020-2035. doi: 10.1161/ CIR.0b013e31826e1058.

3. Ayesha Saleem A, Ali A. Correlation of C-Reactive Protein and Cardiac Enzymes with Angiographic Severity of Coronary Artery Disease in Pakistani Patients with Acute Coronary Syndrome. J Coll Physicians Surg Pak. 2017;27(2):66-70.

4. Falk E, Shah PK, Fuster V. Coronary plaque disruption. Circulation. 1995;92:657-671.

5. Schaar JA, Muller JE, Falk E, Virmani R, Fuster V, Serruys PW, et al. Terminology for high-risk and vulnerable coronary artery plaques: Report of a meeting on the vulnerable plaque. June 17 and 18, 2003, Santorini, Greece. Eur Heart J. 2004;25:1077-1082.

6. Burke AP, Farb A, Malcom GT, Liang YH, Smialek J, Virmani R. Coronary risk factors and plaque morphology in men with coronary disease who died suddenly. N Engl J Med. 1997;336:1276-1282.

7. Ueda Y, Ogasawara N, Matsuo K, Hirotani S, Kashiwase $\mathrm{K}$, Hirata A, et al. Acute Coronary Syndrome: Insight From Angioscopy. Circ J. 2010;74:411-417

8. Erne P, Radovanovic D, Seifert B, Bertel O, Urban P. Outcome of patients admitted with acute coronary syndrome on palliative treatment: Insights from the nationwide AMIS Plus Registry 1997-2014. BMJ Open. 2015;5(3):e006218. doi: 10.1136/ bmjopen-2014-006218. 
9. Alvaro Avezum A, Makdisse M, Spencer F, Gore JM, Fox KAA, Montalescot G, et al. Impact of age on management and outcome of acute coronary syndrome: Observations from the global registry of acute coronary events (GRACE). AHJ 2005;149(1):67-73. doi: 10.1016/j.ahj.2004.06.003.

10. Roffi M, Patrono P, Collet JP, Mueller C, Valgimigli M, Andreotti F, et al. 2015 ESC Guidelines for the management of acute coronary syndromes in patients presenting without persistent ST-segment elevation: Task Force for the Management of Acute Coronary Syndromes in Patients Presenting without Persistent ST-Segment Elevation of the European Society of Cardiology (ESC). Eur Heart J. 2016;37(3):267-315.

11. Alfredsson J, Stenestrand U, Wallentin L, Swahn E. Gender differences in management and outcome in Non-ST-Elevation Acute Coronary Syndrome. Heart. 2007;93(11):1357-1362. doi: 10.1136/hrt.2006.102012.

12. Fanaroff AC, Rymer JA, Goldstein SA. Acute Coronary Syndrome. JAMA. 2015;314(18):1990. doi: 10.1001/ jama.2015.12743.

13. Radovanovic D, Erne P, Urban P, Bertel O, Rickli H, Gaspoz JM, et al. Gender differences in management and outcomes in patients with acute coronary syndromes: Results on 20,290 patients from the AMIS Plus Registry. Heart. 2007;93:1369-1375.

14. Duan JG, Chen XY, Wang L, Lau A, Wong A, Thomas GN, et al. Sex Differences in Epidemiology and Risk Factors of Acute Coronary Syndrome in Chinese Patients with Type 2 Diabetes: A Long-Term Prospective Cohort Study. PLoS ONE. 2015;10(4):e0122031. doi: 10.1371/journal pone. 0122031 .

15. Yang B, Fan S, Zhi X, Wang Y, Wang Y, Zheng Q, et al. Prevalence of Hyperhomocysteinemia in China: A Systematic Review and Meta-Analysis. Nutrients. 2015;7(1):74-90. doi: 10.3390/nu7010074.

16. Shah H, Jan MU, Altaf A, Salahudin M. Correlation of hyperhomocysteinemia with coronary artery disease in absence of conventional risk factors among young adults. J Saudi Heart Assoc. 2018;30(4):305-310. doi: 10.1016/j.jsha.2018.04.002.

17. Pakistan Demographics Profile 2018. https://www. indexmundi.com/pakistan/demographics_profile.html.

18. Rajhans R, Narayanan M. Assessment of arrhythmias in 50 patients of ST-elevation myocardial infarction after thrombolysis: A 24 hour Holter study. Int J Adv Med. 2017;4(3):734-740. doi: 10.18203/2349-3933.ijam20172263.
19. Shah H, Salahuddin M, Altaf A. Association of Left Ventricular Ejection Fraction and gender differences in acute decompensated heart failure patients. J Rehman Med Inst. 2016;2(4).

20. Kawut SM, Lima JA, Barr RG, Chahal H, Jain A, Tandri H, et al. Sex and race differences in right ventricular structure and function. The multi-ethnic study of atherosclerosis - Right ventricular study. Circulation. 2011;123(22):2542-2551. doi: 10.1161/CIRCULATIONAHA.110.985515.

21. Ijaz A, Ijaz A, Saad AA, Zafar S, Safdar S, Rafique S. Renal Dysfunction; In Patients With Acute Coronary Syndrome (ACS) At A Tertiary Care Hospital. Prof Med J. 2017;24(9):1275-1279.

22. Udell JA, Koh M, Qiu F, Austin PC, Wijeysundera HC, Bagai A, et al. Outcomes of Women and Men With Acute Coronary Syndrome Treated With and Without Percutaneous Coronary Revascularization. JAHA. 2017;6(1):e004319. doi: 10.1161/JAHA.116.004319.

23. Torabi A, Cleland JG, Rigby AS, Sherwi N. Development and course of heart failure after a myocardial infarction in younger and older people. J Geriatr Cardiol. 2014;11(1):1-12. doi: 10.3969/j.issn.1671-5411.2014.01.002.

24. Mansouri A, Tasharoie S, Javidee S, Kargar M, Taghizadehghehi M, Hadjibabaie $M$, et al. Streptokinase Adverse Reactions: A Review of Iranian Literature. J Pharma Care. 2014;2(3):120-129.

\section{Author's Contribution:}

AA, HS, conceived, designed and did statistical analysis \& editing of manuscript.

HS, MS, did data collection and manuscript writing. AA, takes the responsibility and is accountable for all aspects of the work in ensuring that questions related to the accuracy or integrity of any part of the work are appropriately investigated and resolved. 